\title{
La trayectoria de Chile frente a la región Asia-Pacífico
}

\author{
Manfred Wilhelmy*
}

\section{GENERALIDADES}

Asia-Pacífico es, por una parte, un tema tradicional en la política exterior de Chile, pero principalmente un área de innovación y desarrollo de políticas, lo que le da un interés especial.

Al comenzar esta síntesis es oportuna la siguiente advertencia: no debería verse la política frente a la región Asia-Pacífico como una línea de acción diplomática que se trataría de plantear a expensas de otros ejes de la inserción internacional del país. Es peligroso basar la política chilena en el lugar común consistente en afirmar que, tal como el Mediterráneo fue el área central de las relaciones internacionales en la

Director Ejecutivo de la Fundación Chilena del Pacífico. Las opiniones expresadas por el autor son personales y no representan puntos de vista de esta institución. El texto es una versión revisada de una conferencia dictada en la Universidad UCINF el 30 de junio de 2010.
Antigüedad y el Atlántico lo ha sido en siglos recientes, el Pacífico es la región del presente y del futuro. Vincular esta supuesta «megatendencia» histórica a nuestras prioridades diplomáticas supone atribuir cierto grado de obsolescencia o marginalidad a algunas áreas político-geográficas, lo que puede inducir a una distorsión en la concepción de las políticas. Más bien, al afirmar la importancia de la Cuenca del Pacífico, y especialmente de la región Asia-Pacífico (que aquí se entiende como la ribera opuesta del Pacífico, desde Rusia y Japón por el norte hasta Nueva Zelandia por el sur), es importante que este polo de orientación de las políticas se integre con otros polos tradicionales de nuestras vinculaciones internacionales en un todo coherente y consistente.

Por otra parte, en la medida en que desde Chile pretendemos reiteradamente servir de «puente» entre el AsiaPacífico y América Latina, Sudamérica, 
o por lo menos el Cono Sur, está claro que no tienen mucho asidero las posturas que pretendan, explícita o implícitamente, disociar a Chile de su vecindario. Ello sin perjuicio de que en el contexto latinoamericano debemos procurar individualizarnos frente a nuestros interlocutores de las riberas asiáticas del Pacífico y por tanto, diferenciarnos de otros en nuestra propia región, ya que de otro modo los países asiáticos que nos interesan no verían ninguna razón para desarrollar con Chile algún tipo de relación privilegiada o más intensa en el ámbito latinoamericano, que de por sí no es una prioridad natural o una preocupación central para dichos países.

Dicho esto, no podemos dejar de ser realistas y debemos reconocer que varios de nuestros vecinos tienen la capacidad de diseñar y ejecutar sus propias políticas y vinculaciones con socios del Asia-Pacífico independientemente de las nuestras, y aun compitiendo con Chile. No obstante, incluso en estos casos es concebible que la oferta chilena de servir de «puente», "puerta de entrada» o «plataforma» pueda resultar conveniente para Chile y sus vecinos, por ejemplo, para determinados negocios de transporte de bienes o para la transformación de algunas materias primas en productos con mayores grados de elaboración ${ }^{1}$.

Sobre este tema, ver Rodríguez Guarachi Eduardo (2006), Chile, país puente, Santiago, RIL Editores - Fundación Chilena del Pacífico, especialmente los capítulos II y III.

\section{AnteCEDEnTES}

En la era de la Independencia, el Libertador Bernardo O'Higgins soñó que el proyecto emancipador americano podría proyectarse hacia el sudeste asiático (término que no se usaba en la época). Concretamente, que tras la independencia de los países sudamericanos debía plantearse el objetivo de liberación de la colonia española de Filipinas. Esto por cierto era utópico, ya que los países americanos carecían de los medios para proyectar poder militar y político a gran distancia, pero la aspiración es reveladora de una visión del Libertador que se proyectaba a través del Pacífico.

En el curso del siglo XIX se dio cierto desarrollo de la navegación entre puertos chilenos y del Oriente, pasando por diversos territorios insulares y tocando ocasionalmente en la colonia de Australia (Nueva Gales del Sur). Sin embargo, los flujos comerciales originados en estos viajes fueron esporádicos y de escaso volumen, y las corrientes de circulación de personas no llegaron a ser importantes.

Con todo, desde fines del siglo XIX se fueron celebrando tratados, estableciendo relaciones diplomáticas y abriendo las primeras misiones diplomáticas y consulares. Un hito importante fue el Tratado de Amistad, Comercio y Navegación con el imperio de Japón (1897). En 1915 se establecieron relaciones diplomáticas con la República de China, en 1945 con Australia y Nueva Zelandia, y en 1947 con 
Filipinas, que recién había accedido a la independencia.

En 1888, Chile había incorporado a su territorio la Isla de Pascua. De esta manera el país llegó a tener cierta proyección hacia el Pacífico insular, aunque no se realizaron esfuerzos importantes por desarrollar este lejano territorio e integrarlo efectivamente al país.

En 1947, accediendo a demandas de intereses balleneros nacionales, el Presidente Gabriel González Videla inició el desarrollo de la nueva política de intereses marítimos de Chile, que cerca de cuarenta años después culminaría con la aceptación general de las instituciones del nuevo derecho del mar, especialmente la Zona Económica Exclusiva de 200 millas. La política marítima abrió una nueva dimensión de nuestra diplomacia territorial y económica y contribuyó a una mayor orientación hacia el Pacífico, aunque obviamente sin una proyección directa a las riberas asiáticas del océano ${ }^{2}$.

En general, la primera mitad del siglo XX, así como las décadas de 1960 y 1970 fueron de poco dinamismo en el desarrollo de vinculaciones chilenas con la región Asia-Pacífico. La industrialización sustitutiva de importaciones tuvo un claro sesgo proteccionista. El comercio exterior se caracterizó

2 Sobre los antecedentes históricos, ver Salazar Sparks, Juan (1999), Chile y la comunidad del Pacifico, Santiago, Editorial Universitaria, Segunda parte, Chile: país oceánico y ribereño del Pacífico. por una marcada tendencia a la monoexportación. La incidencia de las guerras mundiales y de la Guerra Fría en las relaciones exteriores fue, en general, limitativa de las opciones de diversificación geográfica, política y económica de estas.

Con todo, hacia 1970 se estaba desarrollando un renovado interés académico en el tema, especialmente en el Instituto de Estudios Internacionales de la Universidad de Chile, entidad que bajo el liderato de su primer director, Claudio Véliz, organizó importantes eventos y realizó publicaciones sobre el desarrollo de la Cuenca del Pacífico. Estas actividades influyeron en círculos dirigentes empresariales y gubernamentales, aunque las inquietudes predominantes en la agenda nacional fueran de otra índole ${ }^{3}$.

El gobierno de la Unidad Popular dio el importante paso de reconocer el gobierno de la República Popular China como el único representante de China, lo que implicó el término de las relaciones diplomáticas con la República de China en Taiwán. Pero este paso se dio por consideraciones políticas distintas de las del desarrollo de relaciones con la región Asia-Pacífico, tema que no interesaba mayormente a dicho gobierno.

En 1970, el Instituto de Estudios Internacionales organizó la conferencia «Chile vuelve al Pacífico», realizada en Viña del Mar. En 1979, bajo la dirección del profesor Francisco Orrego Vicuña, se realizó en Isla de Pascua el seminario «La Comunidad del Pacífico en Perspectiva». 


\section{ChILE Y LOS FOROS DEL PACÍfICO}

El gobierno militar, que percibió claramente las limitaciones derivadas de su complicada posición política internacional, especuló con la hipótesis de que el desarrollo de nuevas relaciones en dirección al Asia podría aliviar un tanto su situación. Para ello se consideraron varios factores: después del 11 de septiembre de 1973, la República Popular China había optado por mantener relaciones diplomáticas con el régimen militar, a pesar de las diferencias ideológicas entre los dos gobiernos, decisión que seguramente tuvo relación con el conflicto chino-soviético; segundo, en general, no se divisaban actitudes de censura política a las nuevas autoridades de parte de los países del Este de Asia, varios de los cuales tenían sus propios regímenes autoritarios; tercero, ya se percibía que en esa parte del mundo el dinámico desarrollo de la economía japonesa lideraba un proceso al que se unían las economías de Corea, Taiwán, Hong Kong y Singapur, lo que prometía abrir interesantes mercados potenciales para las exportaciones chilenas; y, por último, el general Pinochet y sus asesores estratégicos pensaban que, en términos geopolíticos, la Cuenca del Pacífico tendría una creciente importancia, involucrando a actores de gran envergadura como Estados Unidos, la Unión Sovietica, Japón, China y otros, lo que aconsejaba procurar una mayor presencia en el área para de alguna manera cautelar los intereses de Chile como actor del Pacífico sudamericano.

Visto en retrospectiva, el «incidente filipino» de 1980 — la abrupta cancelación de una invitación oficial a Filipinas por parte del Presidente Ferdinando Marcos encontrándose ya en viaje el general Pinochet y comitiva- aparece como un alto en el camino, sin duda un traspié importante y una humillante ruptura del protocolo, que costó el cargo al Canciller Hernán Cubillos. Pero el suceso no terminaría con el interés del gobierno militar en la región, que se manifestó principalmente en el establecimiento de relaciones diplomáticas y la apertura de nuevas embajadas y oficinas comerciales, especialmente en la subregión del sudeste asiático.

De esta manera, Chile llegaría a contar con embajadas residentes en Tokio, Seúl, Beijing, Manila, Bangkok, Hanoi, Kuala Lumpur, Singapur, Yakarta, Canberra y Wellington. Entre las mencionadas, la única embajada abierta durante el período de la Concertación ha sido la misión en Vietnam (Hanoi). A esta amplia red diplomática se agrega el Consulado General en Hong Kong, representación indispensable considerando la importancia de esta gran plaza comercial, financiera y logística oriental, y la oficina comercial en Taipei, que permite atender el comercio con Taiwán, independientemente de las relaciones con China. Las embajadas cubren los principales países de la región, sin que en nuestra opinión sea necesario en el futuro próximo considerar otras aperturas, ya que el mecanismo 
de las concurrencias permite atender razonablemente las necesidades de representación en países como Brunei, Mongolia y Timor Leste, así como los nuevos países de la ASEAN (Asociación de Estados del Sudeste Asiático), con los que las relaciones son todavía muy pocas. Con todo, dado que de acuerdo con los términos de la Carta de la ASEAN esta entidad ahora recibe embajadas, la eventual creación de una misión ante este organismo regional surge como un tema a considerar.

En síntesis, la red someramente descrita constituye un instrumento que debemos considerar necesario en términos de mantener una presencia oficial, aunque ciertamente no puede considerarse garantía del desarrollo de mayores vinculaciones chilenas con la región Asia-Pacífico. En la práctica, factores como la dotación de recursos, la capacidad de los diplomáticos y personal de apoyo, y la disposición a trabajar con los actores del sector privado inciden en la eficacia de la red de sedes oficiales y cada uno de sus elementos. Sin profundizar en el tema, para los fines de este trabajo basta observar que en general los funcionarios de carrera que se desempeñan en las representaciones de la región Asia-Pacífico lo hacen con notable dedicación y capacidad de análisis de realidades nuevas y complejas, a pesar de contar con pocos medios para cumplir sus misiones. En la medida en que Asia Pacífico se ha vuelto cada vez más importante para la diplomacia y la promoción de las exportaciones, la necesidad de reforzar nuestras misiones con mayores recursos resulta evidente, y debería ser atendida de manera prioritaria.

Para el gobierno del Presidente Patricio Aylwin, concentrado en su objetivo de política exterior de «reinserción internacional» del país, la continuidad del acercamiento con Asia-Pacífico no era algo que pudiera darse por descontado, ya que las prioridades se encontraban básicamente en las principales democracias occidentales y los países latinoamericanos. Sin embargo, los avances logrados en este primer gobierno de la Concertación de Partidos por la Democracia fueron de gran importancia. A nivel regional, en 1991 el gobierno concretó el ingreso de Chile a la red tripartita (pública, privada y académica) del Consejo de Cooperación Económica del Pacífico (PECC, por su sigla en inglés). Ello permitió al capítulo nacional del PECC, el incipiente Comité Chileno de Cooperación Económica en el Pacífico (CHILPEC), coordinado en la época por la Cancillería, adquirir y transmitir valiosas percepciones y experiencias sobre las perspectivas de integración entre economías de la Cuenca del Pacífico. En esta tarea fueron decisivos el talento y la visión de diplomáticos de carrera como el embajador Octavio Errázuriz y el dinamismo de jóvenes profesionales como Cristina Bitar.

Cabe agregar que antes del ingreso al PECC un grupo de dirigentes empresariales, entre ellos los señores Manuel Valdés y Domingo Arteaga, ya habían impulsado la participación chilena en 
la agrupación del sector privado de la región, denominada Pacific Basin Economic Council (PBEC). El PBEC celebró una Asamblea en Santiago en 1983. La evolución posterior del PBEC excede el marco de este capítulo, pero es posible señalar que, en su momento, se trató de una instancia útil para el avance chileno en dirección al Asia-Pacífico. Más recientemente, el PBEC ha perdido importancia, fundamentalmente porque la agrupación no tiene acceso directo a actores políticos de alto nivel, a diferencia de lo que ocurre en el APEC, que en el marco de las Cumbres convoca importantes citas del sector privado (denominadas por lo general APEC CEO Summits). Otro factor que ha afectado al PBEC ha sido el surgimiento en las últimas décadas de una dinámica industria internacional de conferencias empresariales, que ha competido fuertemente con la mencionada red empresarial, socavando su convocatoria en los temas de interés de los altos ejecutivos del sector privado regional.

Volviendo a comienzos de los años noventa, podemos decir que los esfuerzos mencionados, tanto académicos como empresariales y del gobierno, contribuyeron a sentar las bases para la campaña chilena de ingreso al recientemente establecido foro APEC (Asia Pacific Economic Cooperation Forum). Esta ambiciosa iniciativa se vio alentada por el ingreso de México en 1992, pero enfrentaba reservas por parte de países especialmente influyentes como Australia, Japón e incluso Estados Unidos, que no habían identificado a Chile como un actor legítimo en los asuntos regionales del Pacífico.

En el «lobbying» nacional ante el APEC fue determinante el apoyo que Chile logró obtener de Malasia, y posteriormente de otros países del sudeste asiático. Ello se debió a la excelente relación directa que se estableció entre el Presidente Aylwin y el Primer Ministro de la nación asiática, Dr. Mohamed Mahathir. Dicha aproximación nació de coincidencias en foros multilaterales sobre temas de la agenda social internacional que eran prioritarios para los dos gobiernos, sintonía que proporcionó una base de acercamiento bilateral que a su vez se proyectaría de inmediato hacia el foro APEC. Lo anterior, unido a gestiones especiales ante el gobierno de Australia, el Departamento de Estado y del Tesoro de Estados Unidos, en que intervinieron, además de la Cancillería, los ministros de la Presidencia Edgardo Boeninger y de Hacienda, Alejandro Foxley, permitió destrabar la solicitud chilena. El consenso favorable al ingreso al APEC se logró en la primera Cumbre de Líderes Económicos celebrada a fines de 1993 en Blake Island, Seattle, bajo la presidencia de Bill Clinton. La admisión de Chile se formalizaría en la siguiente Cumbre, en Indonesia, asistiendo el Presidente Frei, sin perjuicio de la paulatina incorporación de delegados chilenos a los grupos de trabajo del APEC que, bajo los términos del acuerdo de Blake Island, se venía produciendo en el curso del año $1994^{4}$.

4 Es interesante la detallada crónica de un testigo y participante calificado, el entonces 
El gobierno de Frei impulsó como una alta prioridad la rápida inserción de Chile en los foros de cooperación del Pacífico. En el segundo semestre de 1994, el ex ministro Boeninger, a solicitud del primer Canciller del Presidente Frei, Carlos Figueroa, encabezó la organización de la Fundación Chilena del Pacífico, entidad destinada a conjugar los esfuerzos del sector público, y de empresarios y académicos para potenciar la actividad nacional hacia la región Asia-Pacífico. La Fundación se hizo cargo de la gestión del ya mencionado CHILPEC, y posteriormente (cumpliendo un compromiso asumido en el APEC) asumió, por mandato del gobierno, el carácter de Centro de Estudios APEC de Chile. Una tercera tarea de la Fundación, también por delegación de la Cancillería, sería la coordinación de la participación chilena en el Consejo Consultivo Empresarial del APEC (ABAC, por su sigla en inglés) $)^{5}$.

En septiembre de 1995 en Beijing, Boeninger, en su calidad de presidente del ya mencionado CHILPEC y de la Fundación, asumió la Presidencia de la red PECC, lo que de acuerdo con los estatutos de la organización significó la

Embajador de Chile en Malasia, Jaime Lagos Erazo, "El ingreso de Chile a APEC (recuerdos diplomáticos)», Diplomacia $\mathrm{N}^{\circ} 73$, septiembre-diciembre 1997, pp 13-17.

5 La mejor síntesis del tema sigue siendo Armanet Pilar, Pilar Alamos y Luz O'Shea, Las Relaciones de Chile con los Organismos Multilaterales de la Cuenca del Pacífico (1996)Santiago, Instituto de Estudios Internacionales de la Universidad de Chile-Fundación Chilena del Pacífico. realización en Chile de la XII Reunión General de PECC, un magno evento que contó con la participación de más de mil delegados de toda la región, de otros países amigos, especialmente latinoamericanos, de representantes de organizaciones internacionales, etc. En PECC XII pronunciaron discursos, además del Presidente chileno, el Primer Ministro de Malasia, el Presidente de Brasil, Fernando Henrique Cardoso, el Canciller de Argentina Guido Di Tella (como invitados especiales), el Director General de la OMC, Renato Ruggiero, y el Presidente del BID, Enrique Iglesias. El programa contempló prácticamente toda la agenda de temas de cooperación regional, desarrollados por delegados calificados, además de temas especiales como la crisis financiera asiática que ya se había desatado y el traspaso de Hong Kong a la República Popular China. No resulta exagerado decir que la realización de PECC XII en Chile estableció una base de conocimiento y experiencia que sería indispensable para el ejercicio de la presidencia chilena del APEC en $2004^{6}$.

La participación chilena en foros regionales se completa con, el Foro de Cooperación América Latina-Asia del Este (FOCALAE), originado a fines de 1998 en una propuesta del Primer

$6 \quad$ El libro editado por Álamos Pilar, Luz O'Shea y Manfred Wilhelmy, América Latina y Asia-Pacifico: Oportunidades ante la Crisis (1998) Santiago, Instituto de Estudios Internacionales de la Universidad de Chile-Fundación Chilena del Pacífico, contiene una selección de discursos y documentos de la conferencia PECC XII. 
Ministro de Singapur Goh Chok Tong, al Presidente Frei. A diferencia de las redes regionales del Pacífico, el FOCALAE tiene carácter interestatal (los miembros deben ser Estados soberanos) e interregional, vale decir, es una red asiático-latinoamericana, y por tanto congrega a países del este de Asia y de América Latina, sean o no del Pacífico, sin incluir a Estados Unidos o Canadá, ni a entidades asiáticas no soberanas como son Hong Kong (hoy Región Administrativa Especial de China) y Taiwán (Taipei chino). Cabe agregar que - gracias al pragmatismo de la diplomacia de Singapur- el FOCALAE incorporó a Australia y Nueva Zelandia, países que interesan de manera creciente a América Latina.

El FOCALAE celebró su I Reunión Ministerial en Santiago en 1999, y posteriormente se han realizado algunas reuniones adicionales, la última en Tokio. No obstante, es necesario reconocer que, desde su época fundacional, los gobiernos de los países participantes no han aunado voluntades políticas de alto nivel susceptibles de hacer de este foro un vehículo privilegiado de diálogo y cooperación entre las dos regiones. A diferencia del foro Asia-Europa (Asia-Europe Meetings, ASEM), los mecanismos políticos del FOCALAE no contemplan la realización de Cumbres. El FOCALAE también carece de un mínimo de institucionalidad, lo que atenta contra la efectividad de sus resoluciones y proyectos, que ante la inexistencia de mecanismos o instancias apoyadas por todos los miembros quedan en alguna medida librados a su propia suerte y normalmente tienen escaso seguimiento y débiles mecanismos de ejecución. Ello se compara desfavorablemente con el ASEM, que - sin ser un mecanismo especialmente robusto- cuenta al menos con el apoyo de la Fundación Asia-Europa (ASEF), con sede en Singapur, creada especialmente para la realización de algunos programas de cooperación europeo-asiática En síntesis, no resulta exagerado aseverar que, hasta ahora, el FOCALAE representa para las dos regiones una oportunidad perdida.

Más adelante volveremos al tema del APEC y las nuevas manifestaciones del regionalismo.

\section{Aspectos Regionales Y BILATERALES}

Las dimensiones regionales y bilaterales de las vinculaciones chilenas con la región Asia-Pacífico se complementan, al punto que no resulta muy exagerado hablar de un "círculo virtuoso» entre ambos niveles de relaciones. En síntesis, la política regional pudo avanzar gracias a los avances de las relaciones en el plano bilateral. A su vez, en este nivel fue posible concretar progresos importantes, como los tratados de libre comercio, gracias a que Chile ya formaba parte de los mecanismos regionales, lo que dio mayor credibilidad a sus pretensiones en los ámbitos bilaterales. Los acuerdos de este tipo han proliferado en tal grado que algunos críticos hablan 
Manfred Wilhelmy • La trayectoria de Chile...

de un «spaghetti bowl» de tratados bilaterales. Al respecto, se ha planteado que a futuro una vía de avance sería que la región alcance mayores niveles de integración y cooperación sobre la base de la convergencia de diferentes acuerdos de nivel bilateral.

Gracias a una activa política comercial chilena, al positivo interés de los países asiáticos y — como se señaló- a la presencia chilena en los foros regionales, Chile cuenta actualmente con una amplia red de acuerdos comerciales en el Este de Asia y Oceanía:

- desde abril de 2004 rige el Tratado de Libre Comercio (TLC) entre Chile y Corea del Sur;

- desde octubre de 2006 está en vigencia el TLC con la República Popular China;

- desde noviembre de 2006 rige el Acuerdo de Asociación Económica Estratégica con Singapur, Nueva Zelandia y Brunei Darussalam, conocido como «P4» («Pacific Four», y más recientemente, en el contexto de su eventual ampliación, como Transpacific Partnership (TPP);

- a partir de septiembre de 2007 está en vigencia el Acuerdo de Asociación Económica con Japón; y

- desde marzo de 2009 se encuentra en vigor el TLC con Australia.

El gobierno del Presidente Piñera espera firmar a fines del 2010 el TLC con Malasia, ya que las negociaciones iniciadas bajo el gobierno anterior han concluido exitosamente. Se espera que el próximo socio con el que habrá un TLC sea Vietnam, seguido de Tailandia, con lo que, entre los principales países de ASEAN, solo restaría a Chile concluir acuerdos con Indonesia y Filipinas.

Esta extensa red de acuerdos ofrece amplios beneficios en materia comercial, especialmente cronogramas de desgravación que ofrecen ventajas competitivas en los mercados respectivos, lo que en la medida de una implementación sistemática conlleva un gran potencial de diversificación de productos en los respectivos mercados, con mayor acceso para las exportaciones no tradicionales. Además, diversos tratados regulan disciplinas adicionales aplicables a los servicios, las inversiones, la facilitación del comercio y la cooperación en materias de interés común. En todos los casos, los mismos procesos de negociación han contribuido al conocimiento mutuo entre equipos de funcionarios y representantes técnicos y gremiales de los respectivos sectores privados, lo que ha aportado valiosas informaciones, imágenes recíprocas más diferenciadas y realistas, y antecedentes relevantes, tanto estratégicos como de carácter coyuntural, que resultan útiles para el avance de las relaciones económicas, políticas, y culturales en ambas direcciones.

Idealmente - en términos de la idea de Chile como «país puente»— la red de acuerdos de Chile en Asia y Oceanía podría vincularse con la red de acuerdos en las Américas, que incluye el Acuerdo de Asociación Económica con Canadá (1997), el TLC con México (1999), el 
TLC con Estados Unidos (2004) y el TLC con Perú (2009), además de la asociación de Chile con el MERCOSUR (1996). En términos generales, pensamos que esta complementación sigue en el plano de las aspiraciones y propuestas programáticas.

Con todo, podemos señalar que el área de APEC ha llegado ser de importancia determinante en el marco del comercio exterior de Chile. Dentro de esta, el este de Asia tiene actualmente más importancia que el área Unión Europea, el NAFTA y América Latina como destino de las exportaciones chilenas, aunque la composición de lo que exportamos a esa región es relativamente tradicional (los principales productos del tipo «commodities» representan la mayor parte de las ventas) y la cantidad de actores empresariales sigue siendo relativamente reducida. Los esfuerzos de promoción comercial bajo la normativa de los diferentes acuerdos preferenciales deberían contribuir a que esta situación vaya mejorando significativamente, pero está claro que se trata de un objetivo que solo se podrá alcanzar en plazos relativamente largos.

La situación al año 2008 era, en síntesis, la siguiente: en un total de intercambio comercial chileno de US\$ 124.943 millones, el comercio en el área APEC ascendió a US\$ 67.286 (53,8\%). Las exportaciones a las economías APEC llegaron a US\$ 37.317 millones, y las importaciones a US\$29.969 millones, lo que muestra que APEC generó para nuestro comercio exterior un superávit de más de US\$ 8.000 millones, situación excepcional en América Latina, que contribuyó a un facilitar el financiamiento de ciertos déficit en otros intercambios (por ejemplo, con Argentina), demostrando que la zona APEC ha sido un buen negocio para el comercio exterior de Chile?

Una rápida comparación con los demás socios latinoamericanos de APEC, México y Perú, revela claras diferencias. En el año 2008, el comercio exterior de México alcanzó la suma de US\$ 602.769 millones, de los cuales US\$ 499.342 (un $83 \%$ ) consistieron en exportaciones e importaciones con otros miembros de APEC. Las exportaciones al área APEC alcanzaron a US\$ 250.437 millones, pero dentro de este valor exportado, US\$232.906 millones correspondieron al destino Estados Unidos, lo que contrasta con los exiguos valores de las exportaciones mexicanas destinadas a Japón, US\$2.046 millones, a China US\$ 2.045 millones, y a Australia US\$ 671 millones. En otras palabras, las exportaciones mexicanas están destinadas en una proporción abrumadora a un solo mercado, Estados Unidos, situación que difiere sustancialmente de la distribución relativamente pareja que hemos observado en el caso de Chile.

Por el lado de las importaciones mexicanas ocurre algo parecido, aunque no tan marcado. En un total de im-

Las cifras se basan en estadísticas oficiales publicadas en el libro de Adriana Roldan Pérez (2010), Beneficios y Retos de Colombia en APEC, Medellín, Fondo Editorial Universidad EAFIT-Ministerio de Relaciones Exteriores de Colombia, Cap. 2. 
portaciones de US\$248.906 millones, el origen Estados Unidos da cuenta de US\$ 151.334 millones, China de US\$ 34.960 millones, Japón de US\$ 16.282 millones, y Corea de US\$ 13.527 millones. Y si bien el comercio con APEC dejó un muy leve superávit a México en el año analizado, este se explica totalmente por las cifras del intercambio con Estados Unidos, superavitarias para México en más de US\$ 80.000 millones, mientras el comercio con China, Japón y Corea es fuertemente deficitario para la economía mexicana. A la luz de esta realidad, no debe sorprender que en México la percepción del este de Asia, y particularmente de China, sea más bien de una amenaza a los intereses comerciales del país, percepción que contrasta con la predominante en Chile, donde en general se ve a China como una gran oportunidad de mercado.

El caso de Perú se puede describir como una situación intermedia entre Chile y México. Con un valor total de comercio exterior muy inferior, de solo US\$ 60.262 millones en el año 2008, el comercio con APEC alcanzó a US\$ 32.326 millones $(53,6 \%)$.. Las exportaciones llegaron a US\$ 16.492 millones y las importaciones a US\$ 15.834 millones, o sea, se registró un pequeño superávit favorable a Perú. En las exportaciones, el mercado de Estados Unidos fue el más importante con US\$ 5.874 millones, pero los mercados de China con US\$ 3.720 millones, Japón de US\$ 1.853 millones y Taiwán de US\$ 595 millones también fueron importantes, aunque a niveles sensiblemente inferiores al del primer mercado. Por el lado de las importaciones, Estados Unidos también fue el primer proveedor con US\$ 5.581 millones, seguido relativamente de cerca por China con US\$ 4.062 millones, Japón con US\$ 1.274 millones, y Corea del Sur con US\$ 779 millones. Estas cifras muestran claramente que, tal como México y contrastando con el caso de Chile, el intercambio peruano con los principales mercados del Este de Asia es claramente deficitario.

Sobre la base de la favorable posición chilena en los intercambios con las principales economías de la región Asia-Pacífico, hay consenso en la lista de tareas prioritarias para llevar las relaciones económicas a una nueva y más avanzada etapa de desarrollo: primero, aumentar la cantidad de productos exportados, especialmente en lo concerniente a productos de carácter no tradicional (el caso japonés muestra que esto es factible - Japón ya es el segundo comprador global de este tipo de bienes de exportación chilenos, pero otros mercados, como el chino y los del sudeste asiático, apenas comienzan a comprar productos no tradicionales- eventualmente a los productos no tradicionales cabría agregar oferta de servicios, lo que ya se está intentando en algunos mercados); segundo, en estrecha relación con el punto anterior, es necesario aumentar la cantidad de empresas exportadoras a la región Asia-Pacífico, para lo cual se requiere un trabajo sistemático de prospección de mercados, giras, asistencia y asesoría 
a empresarios de las PYME, etc.; tercero, aumentar las participaciones de mercado y desarrollar mercados donde la presencia chilena es todavía incipiente, como ocurre especialmente en los países de la subregión sudeste asiático, sin duda, en la medida que se implementen sistemáticamente, lo que no es obvio, los TLC, son valiosas herramientas para trabajar en esa dirección; cuarto, atraer inversiones directas asiáticas, un desafío complejo pero susceptible de abordar, considerando las experiencias existentes con otros orígenes de inversiones extranjeras. Todo lo anterior debe vincularse, a su vez, con las tareas de promoción de la imagen de Chile en Asia, tema en que casi todo está por hacerse, sin perjuicio de la valiosa labor de ProChile, de las giras presidenciales y empresariales, de algunas iniciativas culturales - todavía muy pocas- y de la valiosa experiencia que deja el Pabellón de Chile en la Expo Shanghai 2010, donde Chile es uno de los cuatro países latinoamericanos que construyó su propio recinto expositor (los otros son Brasil, México y Venezuela).

Volviendo al APEC y el tema del regionalismo, creemos que cada uno de los esfuerzos mencionados se pueden complementar significativamente a través de un gran énfasis en la presencia y participación regional de Chile. Esto vale especialmente, pero no exclusivamente en el ámbito del APEC. Chile presidió el foro APEC desde fines de 2003 (sucediendo a Tailandia) hasta fines de 2004, cuando entregó la presidencia a Corea. Durante este período, Chile confirmó ampliamente sus credenciales de economía relativamente pequeña pero adecuadamente preparada para la conducción temática del foro. El mérito corresponde a muchos, pero debe destacarse especialmente el eficiente papel coordinador del Alto Representante (Senior Official) de la época, Ricardo Lagos Weber. Más allá de estas tareas de conducción de la agenda, predominantemente de carácter técnico, Chile demostró que la relativa lejanía geográfica no debía necesariamente constituir un obstáculo para un desarrollo fluido de una amplia variedad de reuniones de representantes gubernamentales de toda la región. En el plano logístico y organizativo, fue notable el trabajo del director de la Secretaría nacional del APEC, Milenko Skoknic y de su equipo. En el nivel de conducción, viajaron a Chile numerosos actores políticos - ministros y Jefes de Estado y de Gobierno, que usan el seudónimo de líderes económicos. El Presidente Ricardo Lagos fue un excelente anfitrión de los líderes. También viajaron a Chile los empresarios miembros del Consejo Consultivo Empresarial del APEC (ABAC), presidido el 2004 por Hernán Somerville, y centenares de importantes empresarios convocados a la Cumbre Empresarial APEC CEO Summit, algunos de ellos de países no miembros del APEC, como Colombia, Argentina y Brasil. El CEO Summit fue presidido por Andrónico Luksic C. y contó con la participación de ocho de los 21 líderes visitantes En el plano académico, la conferencia APEC Study Centers Consortium (ASCC) tuvo 
Manfred Wilhelmy • La trayectoria de Chile...

una importante convocatoria. Todo ello dio a Chile una excepcional visibilidad internacional y se combinó con importantes actividades bilaterales, por ejemplo la visita del Presidente chino, Hu Jintao.

Pasado el "momento estelar» de protagonismo en el APEC, la participación chilena en este foro se ha caracterizado por la continuidad y -especialmente desde la perspectiva de los empresarios - por la búsqueda de fórmulas que permitan reencauzarse hacia formas de apertura que, a diferencia de los entendimientos voluntarios basados en el consenso, tengan validez jurídica internacional equivalente a los tratados de libre comercio. Es así como, a partir de una idea planteada por un empresario canadiense en ABAC el año 2004, se ha ido elaborando la propuesta de un área de libre comercio del Asia Pacífico (la sigla inglesa es FTAAP). El miembro de ABAC Hernán Somerville se ha destacado por su protagonismo en este tema. Los gobiernos gradualmente han incorporado la propuesta en sus agendas APEC, aunque como un objetivo de largo plazo más que como algo a negociar pronto. Efectivamente, los estudios acerca de FTAAP indican que la viabilidad del esquema depende de la plena participación de los principales actores comerciales: Estados Unidos, China, Japón y Corea, la que no se encuentra políticamente asegurada. Por otra parte, la heterogeneidad de los diversos acuerdos bilaterales y subregionales permite pensar que la hipótesis de convergencia de todos ellos en esquemas más amplios, de carácter regional, es también una meta problemática. Por ello, en los últimos años una vía intermedia, basada en la expansión gradual del acuerdo «P 4», rebautizado como «Transpacific Partnership» o TPP, se perfila como una fórmula pragmática para una integración amplia, potencialmente profunda y al mismo tiempo jurídicamente vinculante, que incorpore a los miembros de APEC que tengan la capacidad y voluntad de negociar su adhesión. A mediados del 2010, los países que se encuentran en esta situación son Estados Unidos, Perú, Australia y Vietnam, no descartándose que pronto se pudieran agregar otros. $\mathrm{Al}$ respecto, Chile se encuentra en una posición especial que merece ser destacada, por cuanto el elemento «trans-Pacífico", que es esencial en el TPP, se debe precisamente a la participación de nuestro país ${ }^{8}$.

En el ciclo APEC del año 2010, conducido por Japón, un tema central es la evaluación del cumplimiento de la llamada "primera Meta de Bogor». Estas «metas» se fijaron en la Cumbre APEC de Bogor, Indonesia, en 1994, y consisten, en síntesis, en que las economías desarrolladas de APEC se comprometieron con el objetivo de liberalización de sus

8 El tema FTAAP se estudia en detalle en la obra An APEC Trade Agenda? The Political Economy of a Free Trade Area of The Asia-Pacific (2007), de Morrison Charles y Eduardo Pedrosa (eds.) Singapur, ISEAS -ABAC-PECC. Sobre los TLC y su posible convergencia, ver Estevadeordal Antoni y Kati Suominen, (2009) Bridging Regional Trade Agreements in the Americas, Washington D.C., BID. 
intercambios comerciales y financieros en 2010 (primera meta), mientras que el año 2020 deberá haberse alcanzado la plena liberalización de estos intercambios entre todos los miembros del APEC (segunda meta). Al redactar este texto varios meses antes de la Cumbre del APEC de Yokohama (noviembre de 2010) no es fácil predecir la fórmula que escogerán los ministros y los líderes para pronunciarse al respecto. A juicio del autor, lo más probable es que estos actores políticos celebren los logros del APEC en materia de liberalización, subrayando por ejemplo, que en materia de aranceles aduaneros los gravámenes han disminuido de una media de alrededor de $17 \%$ en la época de creación del foro a alrededor de $6,6 \%$ veinte años después, o sea, en casi dos tercios. Y si bien no es fácil atribuir esta importante apertura general a un "efecto APEC», ya que se conjugan en ella medidas a nivel multilateral (OMC), unilateral, bilateral y subregional (TLC), con los programas propios del APEC (no vinculantes, como ya se señaló), es muy probable que los ministros y líderes atribuyan estos progresos a la postura consistentemente liberalizadora del APEC. Al mismo tiempo, dado que no será fácil ocultar las evidentes barreras proteccionistas que subsisten en los intercambios comerciales y financieros, es fácil prever que los actores políticos recordarán que en los 16 años transcurridos desde el anuncio de las metas y el cumplimiento del primer plazo, las circunstancias político-económicas internacionales han variado sustancialmente: entre
1997 y 1999 la crisis financiera asiática azotó fuertemente a muchas economías de APEC; en años recientes, a pesar de la postura pro-OMC de APEC, la Ronda de Doha de la OMC se ha estancado; y más recientemente, a partir de la «crisis subprime» de Estados Unidos, el mundo ha sufrido el embate de la crisis recesiva más severa desde la Gran Depresión. Ante ello, es altamente probable que junto con valorar que no ha ocurrido un retroceso generalizado en materia de intercambios, los actores políticos del APEC subrayarán que el foro enfrenta una importante agenda para el período 2010-2020, durante el cual deberá profundizar la integración entre los miembros desarrollados del foro y lograr avances sustanciales de los demás miembros, en los términos de la segunda meta de Bogor. Al respecto, cabe agregar que Chile, no siendo una de las economías desarrolladas miembros del APEC, se acogió desde un comienzo al plazo del 2010, sometiendo sus políticas al examen correspondiente, lo que sitúa al país en una posición muy sólida frente a los demás?.

Entretanto, ha surgido una corriente vigorosa de propuestas de integración regional entre países de la región AsiaPacífico, en las que no se considera a

9. El tema de las metas de Bogor ha sido analizado por la consultora neozelandeza NZIER para el Consejo Empresarial de APEC (ABAC), «Review of Bogor Goals at 2010», ABAC, junio 2010. El informe concluye, en general, que el APEC puede exhibir importantes logros en materia de liberalización, pero que debe avanzar mucho más para cumplir las Metas de Bogor. 
los países americanos. La Asociación de Estados del Sudeste Asiático (ASEAN) está en el centro de varias de estas propuestas, probablemente porque la entidad, compuesta por países medianos y pequeños, no constituye un factor de competencia real para los grandes actores políticos del Este de Asia como son Japón y China, y en menor medida Corea. Bajo el esquema ASEAN + Tres, el este de Asia se integraría sobre la base de entendimientos económicos y políticos entre los diez países del sudeste asiático más Japón, China y Corea. Sin embargo, dado que en la práctica estos tres grandes actores tienen intereses individuales y sus propias agendas y relaciones recíprocas no exentas de problemas, una variante de ASEAN + Tres es la de ASEAN $+1+1+1$, o sea, entendimientos paralelos entre ASEAN y los países mencionados. El Tratado de Libre Comercio entre China y la ASEAN se inscribe en esta tendencia. Bajo el esquema ASEAN + 6 o East Asian Summit, los países del sudeste asiático formarían el núcleo de un esquema económico y político amplísimo, que además de Japón, China y Corea se extendería a Australia, Nueva Zelandia y la India ${ }^{10}$. También en la propuesta de una Comunidad de Asia-Pacífico (Asia Pacific Community o APC) del entonces Primer Ministro de Australia, Kevin Rudd, la ASEAN se encontraba en una posición

10 Sobre la ASEAN y el regionalismo asiático, ver Brick by Brick-The Building of an ASEAN Economic Community (2007), de Hew Denis, Singapur y Canberra, ISEASAsia Pacific Press. central, aunque en este referente la preocupación principal de Canberra era contar con una agrupación que, a diferencia del APEC, permitiera desarrollar una diplomacia amplia, especialmente en lo concerniente a la agenda de seguridad.

Al respecto, la diplomacia chilena, y más en general latinoamericana, no debería limitarse a observar de lejos los acontecimientos. Un posible mensaje que sería útil transmitir a nuestros interlocutores asiáticos es que esperamos que el desarrollo del regionalismo asiático no tenga lugar a expensas del interregionalismo del Pacífico, que es de la esencia de los foros en los que tenemos presencia, así como del acuerdo TPP, que enfrenta el escenario de su eventual ampliación. En otras palabras, las nuevas tendencias del regionalismo asiático, cualquier que sea la opción específica que prevalezca, deberían considerarse como un complemento y no una alternativa a los entendimientos a través del Pacífico, en los que se han invertido esfuerzos considerables a lo largo de varias décadas de diplomacia. En este tema, se podría agregar, los intereses latinoamericanos se diferencian de los intereses de Estados Unidos, ya que este país, atendida su enorme gravitación internacional, será de todas maneras invitado, si no a integrarse, al menos a dialogar con cualquier esquema o referente asiático, lo que no ocurriría en el caso de los países latinoamericanos. Podría pensarse que un aliado natural en esta diplomacia destinada a no salir de la «pantalla de radar» de 
los asiáticos sería Canadá, ya que los canadienses enfrentarían un riesgo similar al de los países latinoamericanos al no extenderse automáticamente a ellos las consideraciones que los asiáticos tendrían frente a Washington.

Una manera de prevenir el debilitamiento de nuestras asociaciones regionales con Asia y de volver a perfilarnos como el mejor socio latinoamericano de los países de Asia-Pacífico, sería que Chile volviera a presidir el foro APEC Japón el presente año, Estados Unidos el año 2011 y otros países ya lo están conduciendo o lo conducirán por segunda vez. En los próximos años cada vez más miembros del APEC tendrán que asumir este rol, ya que en la práctica la lista de economías disponibles para ejercer la presidencia se habrá agotado (de hecho no cuentan para ejercer la presidencia tres miembros del APEC, que son Papua Nueva Guinea por carecer de los medios, Hong Kong y Taipei chino, porque China no ha dado señales de permitirlo). El costo económico (fiscal y privado) de una iniciativa como la propuesta es conocido y está dentro de lo factible. Chile cuenta con probado liderazgo y capacidad de gestión en la materia. La experiencia del año 2004 fue muy positiva y se puede aprovechar para hacerlo aún mejor en una segunda oportunidad. Se podrá argumentar, como de hecho ha ocurrido privadamente, que el APEC no tiene claro su rumbo, por lo que no valdría la pena conducir el foro. La respuesta a esta objeción no es desconocer que el APEC tiene debilidades, sino señalar que a pesar de ellas mantiene su convocatoria y, junto con la red PECC, es el único referente en el que Chile (además de los otros dos miembros latinoamericanos) tiene una posición legítima y consolidada.

Nuestro pronóstico es que junto con su agenda tradicional de liberalización, facilitación y cooperación para el desarrollo, en los próximos años el APEC va a seguir extendiendo sus deliberaciones en muchos campos de las políticas públicas que son de interés común para sus miembros. En el contexto de un proceso de globalización, que a pesar de muchos altibajos no se detiene, ello permite anticipar crecientes instancias de comunicación y diálogo entre el APEC y otros referentes cruciales, como el G 20 y la OCDE. En los temas fundamentales de política comercial, el APEC lleva la delantera al G 20. En cambio, en la agenda de manejo coyuntural de la situación económica internacional y sus aspectos financieros, el mayor protagonismo pertenece al G 20.

Estados Unidos, Japón, la República Popular China, Rusia, Corea, Canadá, México, Indonesia y Australia son los 9 miembros del APEC que también integran el G 20, o sea, prácticamente la mitad del G 20 son países que forman parte del APEC. Esta afiliación simultánea de actores de gran peso internacional a dos grandes referentes, uno global, el otro regional o interregional, permite pensar que la comunicación entre las dos instancias debería ser factible y útil. Para miembros del APEC que, como Chile, Singapur, Malasia, Nueva Zelandia 
y otros, no están en el G 20 pero tienen interés y preparación técnica en los temas propios de este referente, tender puentes de diálogo entre ambos debería ser de mucho interés. Por su parte, para integrantes del G 20 como Argentina, Brasil, Francia, Alemania, Italia y el Reino Unido, un acercamiento al ámbito del APEC sería también favorable al fortalecer sus vinculaciones con los dinámicos procesos de desarrollo de la región Asia-Pacífico.

\section{LOGROS Y TAREAS PENDIENTES}

Chile viene realizando un considerable esfuerzo de acercamiento a la región Asia-Pacífico. Se trata de una política de Estado apoyada en un alto grado de consenso de los principales actores políticos y económicos del país. Esta base de apoyo contribuye a la estabilidad de la política, entre cuyos logros y beneficios merece destacarse un muy activo comercio con la región, una imagen generalmente positiva, que tiende a diferenciarse en relación con el resto de América Latina, lo que se traduce en cierta credibilidad frente a nuestros interlocutores asiáticos.

Frente a estos logros debemos reconocer que subsisten debilidades y falencias. La gran distancia geográfica que nos separa del este de Asia impone elevados costos de transacción con los países del área. El hecho de que los días de navegación entre Chile y los puertos de la región sean muchos más que en el caso de países competidores, como
Australia y Nueva Zelandia, y que las comunicaciones aéreas sigan siendo indirectas, salvo en los casos de Auckland y Sydney, es un factor de debilidad. El bajo grado de conocimiento de las culturas asiáticas por el público y las élites chilenas no ayuda al desarrollo de las relaciones. Un factor en esta situación es la escasa disposición de las instituciones académicas nacionales a desarrollar programas importantes dirigidos a mejorar el conocimiento de la región Asia-Pacífico (más allá de iniciativas de extensión). Ha correspondido a la generación a que pertenece el autor de estas páginas, formada en moldes occidentales, asimilar nuevas tendencias internacionales y abrir áreas de conocimiento y vinculación no tradicionales a través del Pacífico. Una tarea central de las nuevas generaciones debe ser la ampliación y profundización de estas relaciones. 